\title{
Nonsteroidal anti-inflammatory drug associated diaphragm disease
}

\author{
Aileen McGonigal, David F Moffat, George BM Lindop, William J Gilchrist
}

\begin{abstract}
Summary
We present a case of anaemia and intestinal obstruction in a 78-year-old woman taking nonsteroidal anti-inflammatory drugs who was found to have diaphragm disease at laparotomy.
\end{abstract}

Keywords: diaphragm disease, nonsteroidal anti-inflammatory drug

A 78-year-old woman presented to the Western Infirmary, Glasgow, in June 1995 with a six-week history of fatigue, anorexia, weight loss and upper abdominal pain. She complained of heartburn and nausea, but denied melaena or frank gastrointestinal blood loss. She had a background of osteoarthritis, treated with nonsteroidal anti-inflammatory drugs (NSAIDs) over the previous three years (ibuprofen $400 \mathrm{mg}$ tid for two years, followed by diclofenac $50 \mathrm{mg}$ tid for the year prior to admission). The only other illness of note was ischaemic heart disease resulting in mild congestive cardiac failure, which was being treated with frusemide and enalapril.

On examination she was pale and dyspnoeic, with signs of cardiac failure. Abdominal examination was unremarkable, and faecal occult blood test was negative. Initial investigations revealed marked iron deficiency anaemia (haemoglobin $5.3 \mathrm{~g} / \mathrm{dl}$; mean corpuscular volume $77.9 \mathrm{fl}$; ferritin $22 \mathrm{ng} / \mathrm{ml}$ ), other blood parameters being essentially normal. Despite the negative faecal occult blood test, the most probable diagnosis was considered to be NSAID-induced gastrointestinal blood loss. The diclofenac therapy was discontinued, the patient was transfused, and treated empirically with omeprazole.

Upper gastrointestinal endoscopy performed 48 hours after admission showed a hiatus hernia with no evidence of ulceration or recent blood loss. Barium enema showed only mild diverticular disease. During the remainder of her admission the patient remained stable with no evidence of continuing blood loss. She was treated with ferrous sulphate tablets $200 \mathrm{mg}$ tid, and at the time of discharge her haemoglobin was $11.5 \mathrm{~g} / \mathrm{dl}$.

Two months later she was re-admitted to the department of Medicine for the Elderly, with vomiting and constipation alternating with bouts of diarrhoea. Again, there was no history of melaena or haematemesis. Haemoglobin level had fallen to $9.5 \mathrm{~g} / \mathrm{dl}$, and in addition there was biochemical evidence of undernutri- tion, with low albumin $(29 \mathrm{~g} / \mathrm{dl})$, calcium $(2.11 \mathrm{mmol} / \mathrm{l})$, magnesium $(0.51 \mathrm{mmol} / \mathrm{l})$ and zinc $(12 \mu \mathrm{mol} / \mathrm{l})$. Red cell folate and serum vitamin B12 measurements were normal.

Following admission, she developed clinical and radiological features of small bowel obstruction, and laparotomy revealed multiple ileal strictures requiring ileal resection. Pathological examination of a $28-\mathrm{cm}$ segment of ileum showed circumferential strictures involving the submucosa and mucosa with sparing of the muscularis propria and serosa. Appearances were typical of diaphragm disease (figure). Postoperative recovery was uneventful, and the patient was discharged home 12 weeks after admission.

\section{Discussion}

Although NSAID-induced gastropathy is well documented, the extent of complications involving the small and large bowel has become more apparent only within the last five years. 'Red spot lesions' seen enteroscopically are thought to represent an early stage of mucosal damage which may precede ulceration. ${ }^{1}$ This has been demonstrated in the small bowel, and it has been suggested that circumferential ulceration may be a precursor of diaphragm formation. $^{2}$

'Diaphragm disease' is the name given to the presence of characteristic intestinal strictures caused by NSAID therapy. ${ }^{3}$ The strictures resemble exaggerated plicae circularis, and are macroscopically and microscopically distinct

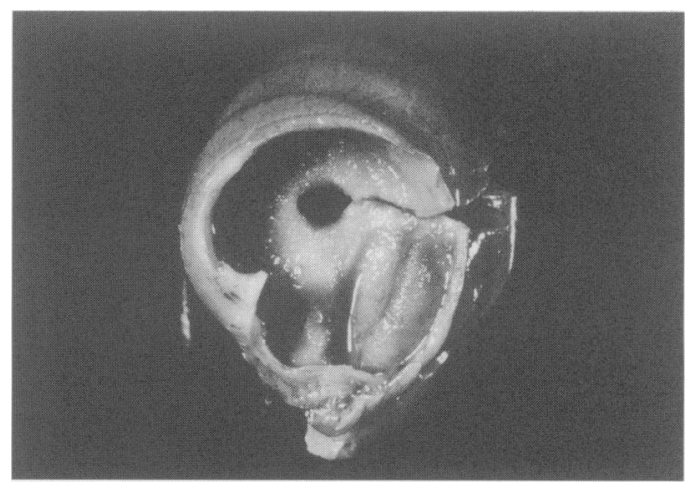

Figure A transverse section through the terminal ileum showing a severe stenosis due to the formation of a diaphragm. The residual lumen measures approximately $5 \mathrm{~mm}$ in diameter. The muscle and serosal layers appear normal, as does the bowel wall on either side of the diaphragm 
from those found in all other types of bowel stricture. The diaphragms are often multiple, and the bowel is compartmentalised by incomplete partitions of mucosa, with normal mucosa intervening.

The pathogenesis remains unclear. ${ }^{4} \mathrm{~A}$ possible mechanism relates to NSAIDs causing reduced mucosal prostaglandin synthesis, leading to circumferential ulceration. It has been suggested that healing causes fibrosis and tissue contraction resulting in the formation of a diaphragm by a 'drawstring' action. ${ }^{2}$ Although most reported cases of diaphragm disease have shown small bowel strictures, similar lesions have also been described in large bowel; as these latter cases have involved the use of slow-release NSAID preparations, a local mechanism may also be implicated. ${ }^{5}$

Imaging of the small intestine is difficult; radionuclide scans may have a useful role but, in general, conventional radiological techniques such as barium studies are unlikely to demonstrate diaphragm disease. Small bowel enteroscopy is a valuable technique for the investigation of undiagnosed gastrointestinal blood loss, and may also detect diaphragms, but is not widely available.

Although the elderly are particularly susceptible to the adverse effects of NSAIDs ${ }^{6}$ these drugs are the fifth most commonly prescribed to patients referred to our Medicine for the Elderly unit (unpublished observations). In

1 Madhok R, Sturrock RD, Capell HA, MacKenzie JF. Enteroscopic diagnosis of small bowel ulceration in patients receiving non-steroidal anti-inflammatory drugs. Lancet 1991; 337: 520 .

2 Going JJ, Convin J, Sturrock R. Possible precursor of diaphragm disease in the small intestine. Lancet 1993; 341: $638-9$.

3 Lang J, Price AB, Levi AJ, et al. Diaphragm disease: pathology of disease of the small intestine induced by nonsteroidal anti-inflammatory drugs. 7 Clin Pathol 1988; 41: steroidal

4 Bjarnason I, Hayllar J, Macpherson AJ, Russell AS. Side

effects of nonsteroidal anti-inflammatory drugs on the small and large intestine in humans. Gastroenterology 1993; 104: $1832-47$.

\section{Learning points}

- the small intestine is an important source of NSAID-related gastrointestinal blood loss

- NSAID therapy can cause intestinal strictures (diaphragm disease)

- diaphragm disease is an uncommon cause of intestinal obstruction

- the elderly are susceptible to the gastrointestinal complications of NSAIDs

addition, ibuprofen is now licensed for overthe-counter pharmacy sale, thus further increasing the consumption of NSAIDs. The prevalence of NSAID use is such that even rare complications, such as diaphragm disease, will increase in incidence and therefore are to be regarded seriously.

The small bowel should be considered as a potential source of gastrointestinal haemorrhage in patients taking NSAIDs, especially when investigation of the gastroduodenal tract and large bowel is negative. The use of prostaglandin E1 derivatives (such as misoprostol) may protect against mucosal damage, ${ }^{7}$ and their concomitant use should be considered in patients such as the elderly who are particularly at risk of gastrointestinal complications of NSAIDs.

5 Gargot D, Chaussade S, d'Alteroche L, et al. Non-steroidal anti-inflammatory drug-induced colonic strictures: two cases and literature review. Am f Gastroenterol 1995; 90: $2035-8$.

6 Gurwitz JH, Avorn J. The ambiguous relation between ageing and adverse drug reactions. Ann Intern Med 1991; 114: $956-66$.

7 Graham DY, White RH, Moreland LW, et al. Duodenal and gastric ulcer prevention with misoprostol in arthritis patients taking NSAIDs. Ann Intern Med 1993; 119: 257 62 . 